\title{
SEGURANÇA, CONFIANÇA E TOLERÂNCIA comandos na sociedade de controle
}

Edson Passetti

\begin{abstract}
Resumo: A passagem da sociedade disciplinar para a sociedade de controle redimensiona os itinerários de segurança, confiança e tolerância. Convoca à participação democrática, consagra uma pletora de diretos, exige adesão aos fluxos produtivos. É a era da disseminação do trabalho intelectual, em que as resistências não se fazem notar por algaravias, mas pelo silêncio.

Palavras-chave: sociedade de controle; tolerância; segurança.
\end{abstract}

Abstract: The transition of a disciplinary society to a society of control reorders the coordinates of security, trust and tolerance. It sounds a call for democratic participation, consagrates a plethora of rights, and demands adhesion to productive activity. It is the age of the dissemination of intellectual labor, in which protest is registered not through chaos, but rather through silence.

Key words: society of control; tolerance; security.

$\mathrm{O}$ s sustos provocam instantes inéditos na história. Eles são descontínuos. Aparecem quando menos se espera, retiram a pessoa de um estado de tranqüilidade, de absorção, de sonho, levando do impacto ao torpor, à embriaguez, ao sono, e educam o assustado a se precaver contra aquele tipo de susto. Provocam ruídos, fazem correr, saltar, gritar, sair do esperado, rir até gargalhar, chorar, atirar-se nos braços desejados, desmaiar, morrer. Os sustos são inevitáveis. Não são poucos e nos pegam. Não cessam: no silêncio uma criança berra, faz explodir uma bola de ar nas suas orelhas, te empurra escada abaixo, com sua ingenuidade e humanidade.

Prevenir pela boa educação é a maneira ética de responsabilizar cada um pelo desassossego provocado com o prazer de assustar, ainda que para isso seja necessário aterrorizar difundindo o medo dos fantasmas, dos sons, dos monstros noturnos, dos esfarrapados, dos pobres que podem te assaltar, dos miseráveis, dos outros. Forma-se um contínuo em que se fica a mercê de uma educação responsável para gerar segurança social e que espera confiantes retribuições. Em nossa sociedade, os pais encontram-se no centro confiável das crianças. Com eles inicia-se a aprendizagem sobre a moral superior, que zela pela segurança do subordinado e estabelece uma relação de mando e cuidados sobre o inferior obediente. Diante da inevitabilidade dos sustos, incluindo o abuso de autoridade do superior, a sociedade exige a educação para a constante restauração da responsabilidade coletiva, suprimindo o exacerbado individualismo egoísta incorporado no tirano, incentivando a tolerante atuação na lida com assimetrias. A intolerância, por conseguinte, de cima para baixo ou vice-versa, compõe um conjunto totalitário inaceitável. Somente a democracia por meio dos direitos universais reconhece a assimetria e afirma a tolerância como maneira pela qual os cidadãos e as elites perpetuam o ideal de aperfeiçoamento pacífico das relações sociais. É tolerando as exceções que se afirmam as regras, os pluralismos, as normas da obediência. Recomenda-se, portanto, de baixo para cima, cuidar para que se evite o tirano, e de cima para baixo, para que se reduzam as assimetrias.

A vida moderna é garantida com base na crença no Estado com monopólio das armas, exército, polícias, e instituições que previnem, asseguram e cuidam das populações e de suas felicidades. Um Estado bem governado protege os súditos de muitos sustos, evitando a eclosão de uma guerra civil (em que uma parte pretende governar 
a sociedade em nome de todos) e do envolvimento num dispendioso conflito bélico externo. O Estado, por meio dos seus governos, precisa dar garantias de segurança. No interior, mostrando-se confiável e capaz de absorver pela prática parlamentar o máximo de demandas formuladas pelos obedientes cidadãos; em relação ao exterior, exercitando protocolos diplomáticos como redutores do belicismo. O Estado é o agente de guerra e o lugar da institucionalização do conflito: ele é o nosso defensor. Mostra saber governar pelos efeitos da representação política e da biopolítica: zela por nós por meio da rotina parlamentar, pelas políticas de intervenção na vida da população e pela diplomacia externa em nome da consolidação da paz perpétua. O sossego oferecido pelo bom governo resume-se em proteger o cidadão dos inimigos de dentro e de fora, e cuidar da vida de cada um, como um pastor que administra a saúde, os traslados e as vontades de seus seguidores.

Do mesmo modo que uma criança abala a ordem das coisas afirmando sua liberdade diante das regras fixas que lhes são apresentadas, o sossego do governo do Estado é abalado por aqueles que agitam provocando riscos. Eles são insuportáveis. Assim como a criança que precisa ser educada, os agitadores devem ser localizados, identificados, castigados e reeducados. Ambos (crianças e subversivos) são caracterizados, pelas leis e pelos saberes científicos, como pessoas perigosas, elementos que pertencem a grupos que necessitam de tutorias, curas, punições, banimentos. Formam, numa só pessoa, um duplo que carece de educação para superar a infância da existência e adentrar à vida adulta responsável dos que trabalham, pagam impostos, votam, cumprem deveres e se vangloriam de obter direitos. As prescrições tolerantes - que funcionam até o ponto em que se possam extrair demonstrações acerca da absorção dos cânones da moral da boa sociedade ao exporem seus limites -, instituem o complementar conjunto punitivo necessário para a sua continuidade. Ultrapassado o âmbito da prevenção geral exposto em leis e normas ao cidadão e ao futuro cidadão (crianças e jovens), o inevitável castigo se reafirma como relação natural. Para uma sociedade produtiva, equilibrada, segura e com redução de assimetrias é preciso confiança nos superiores (dos pais ao Estado e do Estado aos pais). A virtude do moderno cidadão está em demonstrar obediência aos superiores sob a forma de prevenção geral, preferencialmente democrática. Está em confiar em seu Estado por meio de governos que garantam a paz interna e com relação aos outros Estados; na substituição do governo que fere a constitucionalidade e o direito do cidadão, pela via pacífica, legal ou da revolta. Da mesma maneira, todo aquele que atentar contra a continuidade do Estado atenta contra a sociedade. Fica estabelecida uma relação de mão dupla de vigilâncias e cuidados do Estado para com a sociedade e desta para com o Estado, cabendo ao cidadão o papel de soldado das garantias. O Estado moderno resulta da confiança dos cidadãos em uma autoridade superior tolerante capaz de lhes dar segurança diante dos perigos imediatos internos ou externos.

Desde o século XIX, a sociedade disciplinar, apesar dos cuidados e dispositivos de seguranças, vivenciou reviravoltas políticas que foram da tirania à democracia, da democracia ao socialismo, do socialismo à ditadura. Do rei como o monstro traidor do povo configurado pelos efeitos da Revolução Francesa - combatido pelos idealistas democratas que com suas defesas de direitos e divisões de poderes configuraram a continuidade das desigualdades sociais e dos privilégios, e pelos socialistas que conquistaram o Estado pretendendo atingir a emancipação humana, mas apenas construíram ditaduras, terminando reféns dos democratas juramentados -, aos anarquistas, o monstro político moderno foi redimensionado (Foucault, 2001a). Agora, inversamente ao rei, os anarquistas, os monstros de baixo para cima, abalam a sociedade disciplinar por mostrá-la produtiva tanto no capitalismo quanto no socialismo.

A sociedade disciplinar criou aperfeiçoamentos de vigilâncias cujos ápices se encontraram na transformação do campo de concentração em campo de extermínio e do vôo panorâmico do avião em fumegante bomba atômica. Ela encurtou distâncias para lucrar e guerrear de maneiras certeiras. Gerou velocidades instantâneas, começou a controlar o espaço sideral e conseguiu produtividades inimagináveis. A cada busca mais desesperada por obediências, diante da iminência de um outro susto, consagrou necessidades de afirmar um pacificador estratégico temporário, tolerando muitas vezes ditadores como o mal menor; dentre eles, fascistas e nazistas. Democracia e socialismo estatal, até a terceira parte do século XX, rivalizaram como forças políticas preponderantes pretendendo afirmarem-se como a verdade verdadeira. Diante da uniformidade de uma com base no pluralismo ${ }^{1}$ consagrando a maioria, a outra, ditatorial, justificou-se na suposta legitimidade para a realização da justiça social para a totalidade. A massa, acreditando no poder de redução e supressão de assimetrias pelo Estado, fez da democracia e do socialismo suas religiões do rebanho moderno. 
Na sociedade disciplinar, o espaço preponderante de ocupação dos corpos efetivou-se pelo trabalho manual comandado pelo trabalho intelectual. Foi a era das máquinas energéticas. Era das maiorias sob o comando de minorias, de produtividade privada da empresa em conflito com o procedimento estatal, de mercados livres e monopolizados contra Estados intervencionistas e homogeneizadores, de sindicatos em negócios com empresários e Estado, de mecanização e eletrificação, de controles territoriais sobre a população, níveis de escolaridades e saúde, direitos sociais, uma infinidade de idas e vindas que caracterizaram expressões da realização de justiças sociais na iniqüidade. A sociedade disciplinar foi a época da busca de equilíbrio entre produção da riqueza, sua apropriação e gerenciamento de misérias, cujos ápices rivalizaram Welfare State e Estado socialista. Sociedade disciplinar foi investimento no corpo produtivo, o corpo que adquiriu vida num momento podendo perdê-la a qualquer instante; uma sociedade de vivos e mortos convivendo segundo a produtividade e a docilidade política. Vivo era o produtivo, a verdade afirmada pelo inquérito e a disciplina obtida por meio dos exemplos, dos procedimentos, das prevenções e punições regulamentadas. Nesta sociedade, uma parte viva e quase morta recusou a putrefação exigida na vida capitalista. Combateu na luta contra a exploração material e a dominação política liderada por uma minoria sapiente - também capaz de provocar sustos -, feita representante dos trabalhadores e miseráveis, portando nova e superior consciência estruturada. Instalou-se no Estado, pela planificação da economia e consagração do trabalho intelectual, após sua ocupação revolucionária, prometendo levar à dissolução do domínio do capital sobre o trabalho, do trabalho intelectual sobre o manual e da propriedade privada sobre a riqueza social. Despertou a esperança no socialismo de Estado e foi subjugada pela realidade ditatorial.

A sociedade disciplinar foi a era das minorias (elites ou vanguardas) governando as massas (pela democracia ou pelo socialismo estatal), segundo a representação formal ou a representação da consciência em movimento, formalizando a luta pela eqüidade (os democratas em nome da igualdade política, os socialistas autoritários em nome da igualdade econômica): eis o arco que deu nos comandos de segurança, confiança e proteção, na continuidade da dominação em que a sociedade disciplinar se manteve diante de sustos democráticos, ditatoriais, socialistas e libertários provocados aqui e ali. Trata-se de um mesmo arco (de regimes políticos), para o mesmo alvo (as mas- sas) e a mesma flecha (partidos políticos), uma continuidade das representações numa era dominada pela linguagem das metáforas. Venceu a sociedade disciplinar, com ou sem revolução socialista, como continuidade em transformação, assimilando os sustos, educando as crianças e exigindo a consagrada obediência.

\section{ITINERÁRIOS}

Michel Foucault interessou-se pelo que veio a caracterizar como sociedade disciplinar, relacionando os posicionamentos nelas exigidos e ressaltando que a dessacralização do espaço não havia acompanhado o processo análogo ocorrido com o tempo na história. ${ }^{2}$ Avançou, segundo Gilles Deleuze (1988, 1992), anunciando a sociedade de controle que, desde a segunda metade do século XX, provoca a dessacralização do espaço com a comunicação permanente, a convocação à participação na política e na economia e com a organização baseada na disseminação do trabalho intelectual. Se a sociedade disciplinar potencializou a dessacralização do tempo, a sociedade de controle fará desaparecer fronteiras entre público e privado, nação e território, lugar de trabalho e produtividade, homem e cidadão.

A sociedade de controle não abdica das práticas disciplinares, dos funcionamentos por simultaneidade, justaposição, dispersão, proximidade e distância formando redes. Elas, agora, são redimensionadas segundo fluxos, abolindo as fronteiras conhecidas, pela desterritorialização constante, liberando o trabalhador do confinamento territorial rígido. $\mathrm{Na}$ sociedade de controle, o trabalhador, segundo protocolos, poderá circular por outros países independentemente de limites fronteiriços ou permissões circunstanciais. Forma-se uma nova cidadania ampliada sobre a nacional. O trabalhador não está mais confinado a um território segundo a soberania do Estado moderno. Esta foi ampliada, abolindo-se a continuidade de fronteiras, com os Estados nacionais transformandose em Uniões, como acontece desde os anos 90. Novos controles de terra e ar aparecerão, tanto quanto novas resistências. A internacionalização dos trabalhadores ganha nova dimensão como parte da continuidade da internacionalização constante do trabalho, fazendo implodir sindicatos e lutas convencionais. O aparecimento da globalização varre os socialismos para uma nova produtividade com a universalização da democracia, como na Rússia, ou com a manutenção da ditadura, como na China. A sociedade dos limites - como foi a de disciplina em que o 
poder não ocupava lugar algum, formando situações estratégicas enquanto as resistências atravessavam fronteiras de contornos de classe, grupos, pessoas, instituições e direitos -, demarcava itinerários caracterizando os caminhos possíveis, esperados e recomendados para a boa vida em sociedade. Ela criou positividades de poder, caracterizando-se como uma sociedade diferente da sociedade de soberania que a antecedeu e não suprimiu, acrescentando-lhe novos trajetos. Da mesma maneira, a sociedade de controle não destrói o que a antecedeu: redimensiona o domínio de maneira mais sutil.

A sociedade de controle é uma sociedade de segurança que se pauta num triângulo formado pela reafirmação da incerteza assentada no aperfeiçoamento do inacabado característica marcante do trabalho intelectual -, pela confiança nos programas - de governo, organizações e computação - e pela tolerância como maneira de lidar com assimetrias e dissemetrias. Funda a era da democracia, da convocação à participação redimensionando a representação por uma pletora de direitos que suprimem os específicos direitos sociais, anteriormente conseguidos (Passetti, 2003). Constrói-se uma vida em fluxos regidos segundo protocolos, uma vida diplomática em que não prepondera mais o Estado diante do exterior, mas em que se afirma o exterior organizado segundo o modelo estatal sobre o interior: era do cosmopolitismo, da hospitalidade aos assemelhados, da crença na paz perpétua, do empírico, da comparação, do pluralismo e do relativismo cultural. Nem Hegel, nem Marx, mas era de Kant.

Na sociedade de controle exige-se segurança, convocase à participação e demarcam-se novos itinerários (programas) que pretendem orientar o trânsito nos fluxos. Da mesma maneira que a sociedade de soberania e disciplina, a sociedade de controle depende de itinerários, de localizadores, agora de terra, mar, ar e do celestial. A representação das partes para garantir o todo combina-se com a participação direta de cada agente econômico, fazendo com que as negociações se territorializem segundo negociações locais, superando as atribuições nacionais dos sindicatos. $\mathrm{Na}$ sociedade disciplinar as representações se nacionalizavam; na sociedade de controle exigem-se flexibilidades, combinações de elementos locais, com regionais, nacionais e transnacionais. O fluxo produtivo orienta-se sem espaços demarcados e a representação política, que combinava seletividade eleitoral (partidária) com as demandas organizadas (movimentos), visando influir na governamentalidade, cede vez à participação imediata na produção por meio de criação, aperfeiçoamento ou superação de programas econômicos que se expandem para os fluxos não-governamentais articulados com governos. Os lugares vão dando vez aos fluxos e as redes com seus nós e espaços de localização não são mais lugares característicos atravessados por relações de poder e resistências. As redes são elas mesmas atravessadas por fluxos que perfuram nós, vazam dos espaços demarcados, misturam-se a outros fluxos que se atualizam orientando itinerários, formando mapas de relevos de superfícies e profundidades e mapas celestiais, em que profundidade e superfície se confundem. Não há mais itinerário de ida e volta, apenas fluxos atualizados: nesta sociedade, o fim é estar no meio e na mídia.

A convocação à participação traz outra novidade. Ela pretende manter hierarquias dissolvendo as resistências, naturalizando as relações de poder como inevitáveis domínios e perpetuar assujeitamentos mediante novos processos de subjetivação, que vão da auto-ajuda à ajuda ao alheio, num espetáculo contínuo de filantropias e de multiplicação das compaixões que pretendem integrar a todos: quem é produtivo, quem é morto circunstancial, a moralidade e a piedade. Os corpos não precisam mais da força e da perfeita compleição físicas: a produtividade exige os comandos do cérebro e seus resultados devem mostrar a saúde e a jovialidade da pessoa. O poder positivo e produtivo da sociedade disciplinar é superado, sem ser suprimido, pelo poder relativista da sociedade de controle, de comunicação contínua, de avaliação constante. A qualquer momento poderá haver algo produtivo emanando de um cérebro. O hacker que hoje abala a segurança dos programas de computador pode ser daqui a instantes o seu anjo da guarda. A operação ilegal que você acabou de praticar em seu computador, será corriqueira e legal com um novo programa. Linguagens de poder e religião misturam-se no interior da programação com a mesma destreza que o puritanismo tomou as teorias da administração no século XIX e XX, e a mesma esperteza com que acomodaram as comunicações constantes, a partir de Elton Mayo (Tragtenberg, 1974). Na sociedade de controle, diferentemente da disciplinar, atesta-se democraticamente que ninguém está morto-vivo para sempre; faz-se crer, pelos mercados e pelas políticas transnacionais, que haverá luz no final do túnel e segurança para todos, desde que haja confiança e tolerância: os fluxos precisam me apanhar, a vida está dentro deles, numa velocidade que exige que você a domine para ser absorvido(a), não se perder no itinerário e cair fora dele.

Os espaços planetários de superfície e profundidade, pelos quais os navegadores chegavam na época moderna 
às descobertas de outros continentes, geravam implicações que oscilavam entre os empreendimentos dos Estados, das companhias e das atuações de corsários, todos guiados pelo barco, singrando os mares, as superfícies lisas, descobrindo e colonizando lugares novos, passíveis de efetivação de uma certa utopia. Eram lugares que se transformavam em territórios, incluíam e dizimavam populações nativas que passavam a viver segundo um governo central. Os programas de conquistas siderais alcançados após a II Guerra Mundial redimensionaram os locais, as extensões, os posicionamentos, os navegadores e seus protocolos. Agora as pessoas deslocam-se para habitar territórios não mais apenas de barcos, navios, submarinos e aviões, mas atravessam continentes pela informatização, visitam lugares, conhecem pessoas (falam com elas, escrevem para elas, reconhecem-se em movimento) pelo telefone, televisão e computadores móveis. Não há mais lugar para se trabalhar, tudo ficou móvel, em fluxos pelos itinerários da sociedade de controle. O mar cedeu lugar ao ar, o barco ao avião, os foguetes aos satélites e às estações orbitais, a fábrica à empresa, o operário ao funcionário, as multidões de pessoas - distribuídas como fragmentos de massa, pelos espaços públicos, segundo o multiculturalismo, atuando nas praças e na Internet - substituem classes, povos, grupos e massas; cada pessoa está remetida a mais de uma referência simultânea segundo a pletora de direitos e exigências do trabalho: o especialista cedeu lugar ao polivalente, a moral ao moralista e à transcendentalidade da ética. As diversidades dos exercícios múltiplos entre soberano e súditos nos sentidos ascendentes e descendentes de poder, as vigilâncias panópticas criando positividades de poder com base na utilidade do corpo produtivo e sua correlata docilidade política combinam-se com as infindáveis expectativas de produtividades pela participação que a sociedade de programas, comunicação veloz e convocação constante espera de cada um. Os itinerários são conhecidos e reconhecidos, situados, redimensionados e atravessados cada vez de maneira mais rápida que a anterior. Cada alfabetizado ou alijado eletronicamente gera capacidade para ler e acoplar linguagens e nova carência iluminista, decodificar secretos enigmas, gerar programas, sabotar.

A sociedade de controle forma infindáveis bancos de dados e nos apanha divisíveis, não mais como população mas como "dividualidades", segundo os fluxos: não se representa mais uma multiplicidade de papéis segundo o posicionamento, mas transformações constantes, metamorfoses de acordo com o programa. Não há mais massa clamando pelo líder e o risco da dissolução do indivíduo. Como multidão, configura-se uma profusão de "divíduos", uma multicultural forma de existir como ser cosmopolita, que busca saturar a ação com permissões e protocolos. A multidão age segundo os programas, é convocada, encena suas passeatas, atos, simulações, intervenções estéticas que apartam os miseráveis, e depois regressa feliz, segura e protegida para suas residências, por ter seguido diplomaticamente os itinerários, por investir em mudança segundo a ordem. É preciso outra globalização (Hardt; Negri, 2000): este é seu limite. ${ }^{3}$ A passeata está incorporada à felicidade geral, ao bem-estar de todos, não assusta mais, não gera riscos e testa programas de segurança. Consagrase a polícia nas ruas desde a criação dos programas de "tolerância zero" iniciados pelos estadunidenses, nos anos 80 , como política de direito e em pouco tempo incorporada pelas esquerdas estatistas (Wacquant, 2002; Bourdieu, 1998). Ampliam-se as funções de polícia de reprimir e cuidar, punir e prevenir. Ela passa a ser também uma forma de zelo pela própria conduta, criando-se a polícia da polícia, desdobrando-se vigilâncias.

$\mathrm{Na}$ passagem da sociedade disciplinar para a sociedade de controle o outro ainda prepara um susto inevitável. Vive-se o tempo em que a passeata e as mobilizações nas ruas devem ocorrer segundo regras acordadas antes entre advogados e polícia; advogados, polícia e mídia; acertos entre governo, organizações não-governamentais e mídia. Correto: a política da correção tem duplo sentido, o da retidão moral e o do itinerário recomendado. Exige-se um viver feliz para além de nós, com mais e mais pastores eletrônicos (do anchorman ao líder religioso) desvendando desconhecidos siderais, criando parcerias surpreendentes para a até então diplomacia unilateral da sociedade disciplinar. Não está mais no centro do saber a relação finitude individual/infinitude da espécie. Não há mais o Homem como identidade aglutinadora. O humanismo renascido se transfigurou em humanitarismo. A grandiosidade transcendental de um é trocada pela etérea luminosidade dos efeitos midiáticos instantâneos do outro. Cada um aprende a ser solidário com o que está em evidência, não havendo uma direção a ser seguida (assistir aos pobres, aos doentes e aos abandonados), mas apenas escolhas sinalizadas pelo acordo filantrópico, sob a forma de fórum temático, nacional e internacional, com realização de agenda, uma profícua proliferação de velozes celebrações entre governos, mídias e organizações não-governamentais. A era da liberdade e da igualdade cede vez à época da fraternidade. 
Não se está mais sob o signo da liberdade negativa do liberalismo impedindo o que consagra a lei. Agora a coisa é pessoal, implica auto-censura, elogio às condutas, reconhecimento dos organizados, culto à ética da responsabilidade como o politicamente correto. A política está dentro e fora das instituições governamentais, cumpre itinerários. Não surpreende mais a noção moderna de política elaborada por Michel Foucault: a política é uma guerra permanente por outros meios, atravessando as existências, definindo comandos e obediências, disciplinando em lugares, e agora também comunicando em fluxos, exigindo polícia, consagrando a segurança. Não há tolerância sem perpetuação de relações assimétricas, e, como política correta, a tolerância tem por utopia o zero, a sua própria negação, a intolerância: os termos se misturam, relativizam-se e não se sabe mais o que é uma ou outra; apenas que é preciso perseguir o dissidente, o perigoso, o monstro. No passado recente ficava claro quando um conservador considerava o socialista intolerante; agora eles aprendem entre si e concordam sobre os alvos, como se depreende desde a sistematização elaborada por Anthony Giddens (1995).

Diante da pletora de direitos, exige-se a denúncia em nome da ética, da moral, da sobrevivência, da tolerância zero. Denúncia de vivos sobre vivos, humanos ou natureza representados por organizações. A vigilância por cada um, em nome da sociedade e do Estado para o corpo são. É preciso regras para tudo, uma moral sólida regida por éticas responsáveis, aplacando os sustos: é preciso seguro diante da Aids, do pedófilo, do sexo. O relativismo prepondera pacificando o sexo em casamentos indiscriminados entre heterossexuais e homossexuais ou homoeróticos. O sexo não está mais excluído, como afirmou Foucault em $A$ ordem do discurso. Ele deve estar incluído, transitar livremente, desde que pacificado e policiado, como se fosse possível cessar a transgressão, o que permanece surpreendente, o susto. Espera-se tolerar o que for possível acomodar, identificando e combatendo os outros, os monstros.

Buscam-se parcerias e potencializações do finito-ilimitado (do indivíduo dimensionado como dividualidades, envolvido com nanotecnologias de cura e reprodução), provocando controle dos fluxos, demarcando interfaces, confirmando múltiplas diplomacias, pluralismo político, valorização da participação em todos os empreendimentos em nome da colaboração e da tolerância, tendo por meta conter sabotagens e aperfeiçoar itinerários. Sociedade de controle é sociedade de segurança, de confiança nos programas, de tolerância, veloz e inacabada; consagrando o ideal liberal da razão competente e da sociedade aberta, o liberalismo conservador pluralista, o comunismo de multidão.

\section{ASSUJEITAMENTOS}

Sabemos desde tempos remotos que os itinerários são possíveis de registros em diversos objetos e que estes funcionam como mapas. Ali encontramos os desenhos que mostram, segundo as sociedades, os caminhos para se chegar a um lugar ou até mesmo as suas características mais precisas naquele momento. $\mathrm{O}$ conhecimento acumulado e sintetizado no mapa envolve distâncias, relevos, regime dos ventos ou marés, múltiplas referências sinteticamente condensadas em signos e escalas, mostrando os itinerários de deslocamentos em direção a lugares, segundo critérios universalizantes ou singulares códigos aguardando decifradores. Os mapas são corrigidos à medida que se usam, remetendo à precisão e facilitando alcançar o alvo. Saberes específicos acumulam-se para realizar a tarefa de traduzir a versão atual do itinerário inicial num outro objeto de uso durável, próximo à perfectibilidade. Mapas desta natureza nos levam a lugares conhecidos e também ao ponto de inflexão para uma nova descoberta. O objetivo de suas existências e permanências está na criação para o uso de uma cartografia geral do planeta, na qual se encontram outras múltiplas e parciais cartografias como a dos países, das cidades, dos bairros, dos seus rios, correios, fábricas, postos de assistências, delegacias, prisões, cemitérios, escondidas armas de dizimação em massa, armazéns de armamentos regulados por tratados internacionais, sistemas circulatórios, zonas de infecção e peste. Os mapas se multiplicam, compartimentalizam informações e estão dispostos segundo regimes de poder de manuseio, leituras e decifrações de segredos.

Os cartógrafos detêm um saber centralizador elaborando mapotecas de itinerários que colaboram com a produção da riqueza: identificam minas e fontes de extração das profundidades, esquadrinham cidades em centros e zonas periféricas, expressam graficamente o poder das estatísticas, visibilizando as constatações e metas do controle, delimitam trânsitos populacionais, confinam grupos. A cartografia de itinerários funciona também para controle de população, prática de Estado e de biopoder contemporâneo.

Os mapas são geradores de confianças no traçado para encurtamentos ou detalhamentos de distâncias. Neles es- 
tão registrados os itinerários de confiança na sociedade disciplinar, produzidos por quem vigia (e todos vigiam; esta é a produtividade extraída dos corpos na sociedade disciplinar e que ultrapassa os efeitos da relação hierárquica descensional). Nos simples mapas de deslocamentos que orientam o motorista de ônibus para o trajeto, tanto quanto nas cartas constitucionais, códigos civis e penais, sistemas biológicos, físicas espaciais, diagramações de fábricas, instalações elétricas na rua, no escritório, na própria residência, os mapas confiáveis registram itinerários, conhecidos por quem deles faz uso, e suas sobreposições propiciam cartografias dos corpos planetários, continentais, mares, pessoas, coisas e de seus respectivos posicionamentos.

Na sociedade de controle, o corpo da população deixa de ser o alvo do Estado. Não se pretende mais dele extrair, pela disciplina, o máximo de energias econômicas para reduzir as forças políticas de resistências, esperando docilidades. Persegue-se a convocação à participação numa velocidade capaz de suprimir resistências, integrando a todos. Uma nova era de produtividade toma a dianteira e desloca-se para o interior do corpo, para os nervos, superando a mecânica industrial para afirmar a programática computacional. Deslocamento da subordinação do trabalho manual pelo trabalho intelectual de planejamento, de domínio no capitalismo e no socialismo, para a primazia do trabalho nervoso, pessoal, narcisista, em que o trabalhador é chamado a atuar como criador, obtendo a materialidade da transcendência. $O$ trabalho intelectual não mais organiza o trabalho manual, mas o dissolve em robótica e em computação. No limite - se for possível falar em fronteiras na sociedade de controle - permanece inabalada a noção de política como guerra prolongada por outros meios, acrescida, a partir de agora, da difusão da iminência da paz eterna a ser conseguida pela afirmação das práticas democráticas no trabalho e na política. Imateriais saberes convocam cada um a participar na economia política dos fluxos, em que os territórios demarcados são superados pela desterritorialização constante. Aos poucos, a autoridade localizada na hierarquia em pessoa ou procedimento burocrático é substituída pela atuação nos programas, revitalizando-os, criando novos, ou apenas utilizando aplicações, estabelecendo itinerários no interior de uma economia intelectual. Se no passado a lógica exigia excluir, agora a miséria criada pela riqueza (em todos os cantos do planeta) e docilizada pela democracia (ou pelas tiranias religiosas) é incluída: não estamos mais num processo de formação da riqueza das na- ções ou das classes, mas numa potencialização da riqueza planetária; não mais guerra das raças ou luta de classes, mas convivência na cidadania (o paradoxo que mantêm o outro como o mesmo). O outro não é mais o selvagem, o bárbaro, o oriental, mas o indivíduo ou grupo subversivo que reafirma para o civilizado a resistência à sua inferioridade diante do civilizado, segundo seu próprio padrão. Trata-se do efeito da retórica relativista da pacificação, consagrando a proliferação de guerras rápidas e devastadoras, por meio de agenciamentos de organizações internacionais, mobilizações de organizações não-governamentais, bravatas de políticos de Estados inexpressíveis, associações de forças estatais para rivalizar com a força do Império. Há guerra e inevitavelmente, guerrilhas, eternas batalhas de extermínios em nome da democracia, dos direitos, da tolerância, da segurança (na sociedade disciplinar contra as armas nucleares, na de controle, inaugurada com a guerra de prevenção contra armas biológicas), do cidadão.

A inclusão não se dá apenas nas circunvizinhanças entre legalidade e ilegalidade como na sociedade disciplinar, segundo a lucratividade da segurança, transformada não mais em locais de controle de zonas que iam da polícia ao exército. Convocado a participar, cada cidadão é intimado a denunciar, vigiar, defender bens e valores. Uma moral de civilidade cosmopolita se forma e se fortalece, exigindo ética de responsabilidades acrescidas de cuidados com os outros e zelo pela conservação de seus bens e saúde. É preciso policiar: com guardas armados, comunitários, programas de segurança nas periferias e nos computadores; policiar a si próprio para poder ascender, cuidar do outro para ele vir a ser incluído, proteger-se das balas e dos vícios, rejuvenescer. Recomenda-se policiar o próprio corpo porque na sociedade de controle exige-se jovialidade, sorriso, bem-vestir, polimento, o elogio ao outro como forma de prestígio obtido e reconhecido, nivelamentos trazendo cada outro para próximo de si, humanitariamente. Hermes precisa encurtar distâncias com velocidade. Não há mais mapas ou itinerários registrados em objetos. Os caminhos são traçados de maneira efêmera pelos fluxos, e a cartografia é cada vez mais móvel, tanto quanto os mapas se tornam minuciosos em pormenores, do planeta às bactérias.

Da mesma maneira que a economia vai da superfície e profundidade ao espaço celestial, os surpreendentes momentos siderais e os sustos imprevistos é que ensinarão a elaboração de novas cartografias. A sociedade de controle nos convoca a participar democraticamente da econo- 
mia dos programas. Ela nos faz acreditar que cada um detém o domínio da produção, numa fase, num instante, o saber do poder. Ao nos levar a constatar que participamos diretamente na construção da produção, aparece a perplexidade diante do risco de subversão, lado a lado com o incentivo à participação democrática. Inevitabilidade do susto e eficácia de contenção se rearranjam. A participação deve ser vivida por todos, redesenhando a igualdade política liberal e a igualdade socialista de acesso aos meios de produção, como igualdade de acesso à dinâmica produtiva. A participação é para todos porque todos podem ser acionistas, investidores, inventores.

O inabalável poder da estatística como poder de Estado sobre a população permanece incólume, aperfeiçoado pelos diagramas e pelas projeções que podem ser reelaboradas a cada efeito surpreendente. Da mesma maneira, permanece a propriedade sobre os meios de produção. Seguem, na sociedade de controle, outros assujeitamentos que acoplam punições e disciplinas, prisões e liberdades assistidas, manicômios e hospitais-dia, amputações e próteses, abulimias e flacidez, drogas ilegais e drogas medicadas, psicanalistas, psicos, socios, antropos, disciplinares; inter, multi, pluralistas prefixos para designar uma reforma constante nas relações de saber e poder. Estado e organizações não-governamentais ajustam objetivos, interesses, negociações e domínios, caracterizando a era da vida fundada na confiabilidade nas reformas, na tolerância com os programas governamentais escolhidos democraticamente por eleições regulares, na busca de segurança na polícia, no exército, no sindicato, no patrão, no chefe, no pastor, na casa, como elogio à fidelidade, o ideal de felicidade.

Nesta sociedade, espera-se por silêncios, sorrisos, sussurros, acertos, gestos comedidos, assentimentos, negociações abafando discordâncias, confiando em segurança nas instituições e consagrando a tolerância. Nela, deve-se evitar o berro, a gargalhada, a contestação, o desassossego, o incômodo. A algaravia proletária da sociedade disciplinar definitivamente está pacificada, o ouvir está normalizado pela escuta, o grito pelo gemido. As empresas estão limpas como o hospital, como a oficina de aviões, navios e automóveis, os espaços de guarda de computadores, a escola eletrônica (que acomoda ensino, cultura corporal, dinâmica local, procurando pelo efeito da participação imobilizar a população no local, gerando a crença de que não há nada melhor do que melhorar o lugar onde se mora, fazendo da periferia autênticos campos de concentração sem arame farpado), a base de lançamentos de satélites, tudo limpo, habitado não mais pela fuligem, graxa e lama, mas, agora, por bactérias e vírus. A sujeira permanece lá longe de onde se reciclam esgotos e lixos, nas periferias onde moram pessoas com as espeluncas dos seus equipamentos sociais. O mundo do trabalhador intelectual é seguro, vigiado eletronicamente, comandado por programas informacionais, divertido segundo a televisão a cabo, rápido e ágil de acordo com a produtividade computacional que torna quase tudo obsoleto em pouco tempo, repleto de sincretismos religiosos e musicalidades, feito para um cidadão cosmopolita.

Velocidade. O falso é também vitorioso. Como parte constitutiva também relativiza: a roupa de grife para quem tem, com falsa etiqueta para quem tem menos. Novos piratas atacam nas praças, nas feiras e nos computadores derramando cópias, abalando a segurança e exigindo seguradoras de seguranças. Nesta sociedade importa parecer igual e para tal a igualdade se explicita pelo direito universal à diferença caracterizando a nova uniformidade. Ninguém é mais classe, isso ou aquilo, é cidadão, multidão. Pague e obtenha. Participe e serás bem quisto! A sociedade de controle inclui, ainda que você jamais chegue a desconfiar que está dentro permanecendo fora.

Assujeitamentos ${ }^{4}$ são intermináveis capturas de nós mesmos e auto-censura, fazendo cada um súdito de si, do outro, do que inibe o auto-governo. É preciso crer que dependo do outro, da sua superioridade, da nossa capacidade de reformar, de obter uma cidadania universal. De ser trabalhador com as territorialidades expandidas segundo a superioridade de povos europeus, nivelamento entre sul-americanos, daqui deste lugar no Brasil, na América do Sul, no hemisfério Sul, transitando como capitais via fluxos eletrônicos, mas ainda limitado segundo a territorialidade soberana do Estado do Brasil ou da União Européia. Como trabalhador da União Européia sou mais livre que antes, minha prisão voluntária tem outros muros que não são os das cercas eletrificadas, ou do território nacional, do derrubado vergonhoso muro de Berlim ao fortalecido muro que separa Estados Unidos do México. Os trabalhadores do Brasil também beneficiam-se desta conquista. Eles têm ampliado seu espaço territorial livre de ação, segundo a procedência nacional de seus antepassados imigrantes, fazendo soar uma complementar mistura de direito universal e direito de herança, reafirmando o privilégio: o descendente de europeus tem mais liberdades de trânsito que os demais, ainda que permaneça sob o controle universal das emissões de passaportes, vistos, permissões. Os descendentes de escravos adquirem 
vez por meio de políticas afirmativas (distribuindo cotas para acesso a bens culturais); e, enfim, redimensiona-se o pluralismo que no passado se ajustava a relações entre etnias, raças e religiões como aglutinadores de indivíduos livres. O liberalismo conservador se metamorfoseia em neoliberalismo, liberalismo social...

A vida desterritorializada redimensiona fronteiras. Não é só território, nem corpo produtivo e obediente o que importa na sociedade de controle. O planeta é o corpo a ser preservado pelos trabalhadores saudáveis atendidos pelos seus respectivos seguros (propriedade, saúde, vida...). A prevenção geral entre humanos desloca-se, então, para o planeta: selvagem e civilizado passam a compor o duplo complementar. No mundo do espaço celestial a biopolítica cede lugar à ecopolítica. Tudo se desloca para relações complementares entre o exterior e o interior. ${ }^{5} \mathrm{O}$ investimento do Estado deixa de ser na produtividade do corpo. Ele agora destina-se ao corpo saudável, intelectual e a cuidados do planeta no cosmos. De resto, organizações não-governamentais e filantropias administram o que restou. Se os trabalhadores intelectuais participam diretamente no mundo dos programas, os demais participam pela crença na reforma, na melhoria das condições de vida. Enquanto a economia globalizante atravessa o planeta, o cidadão comum fica parado, pregado no chão diante da televisão, formando a grande multidão diante da TV, o panóptico invertido. Para alguns, vida longa, chips, alterações genéticas, novas tecnologias. Para os demais, o lixo do silício. Os assujeitamentos na sociedade de controle formam subjetividades que defendem segurança, no limite da tolerância zero, lá na periferia, onde continua nascendo o pedreiro e o presidiário, o infrator e o perigoso, o crime e o delinqüente, o seguidor do pastor, o pobre mortal voltado para a auto-ajuda, para receber ajuda, para ajudar, a pessoa atravessada pelas regras do obsoleto itinerário. É pela confiança na superioridade do outro, nos protocolos, que seguem os condutores, que desestabilizam democracias pela possível reemergência da ditadura. De fato, a sociedade de controle traz a democracia para a produção, os fluxos econômicos como mercados, nos moldes liberais. A democracia política fica restrita aos efeitos relativos, midiáticos e de sondagens, atestando a eficácia dos objetivos dos regimes autoritários, instituídos por meio de golpes de Estado, desde os anos 60, que prometiam normalidade democrática. Diante disso, interpuseram-se imprevistos gerados pelos efeitos de guerra, como intolerâncias transnacionais (a repercussão da tolerância zero em âmbito internacional), redesenhando a in- tolerância ocidental do passado que se fundamentava na negação do socialismo; agora, na sociedade de controle, ela se projeta pelos intransigentes grupos anti-americanos armados vindos do oriente, com forte inspiração religiosa, que compõem o arco que vai dos palestinos ao terrorismo sideral inaugurado com o episódio de 11 de setembro de 2001 contra o símbolo capitalista, as torres gêmeas do World Trade Center.

\section{SILÊNCIOS}

Silêncio, a música que emana deste ambiente é a do dedilhar no teclado do computador. Silenciosos e solitários eles navegam pela Internet, trabalhando e se divertindo, estudando e conversando, produzindo e participando, vigiando e assegurando protocolos confiáveis. Tolerantes, assistem invasões por vírus, acionam seus programas de segurança, clinicam os computadores. Mas não há só o silêncio decorrente dos ruídos provocados pelos dedos suavemente sobre as teclas. Há também múltiplas sonoridades musicais e visuais celebrando a continuidade solitária. Tudo muda rapidamente para parecer mais novo, ágil, jovial e completo: a voz está incorporada ao comando, brevemente a pele e os nervos, o calor, o hálito, o estalido. Sobre este silêncio e esta solidão irrompe a musicalidade anarquista de John Cage (Ferrua, 2003), resistências. ${ }^{6}$ Sem a musicalidade do silêncio para estancar e surpreender só há fluxo a atravessar, como uma adaga que penetra o peito, gira $180^{\circ}$, e ao sair deixa uma mortal hemorragia; como uma bactéria que invade o seu interior burlando mapas, desviando de antibióticos, destruindo. Isso é pouco mais que um susto, uma sabotagem. Um silêncio é um susto.

\section{NOTAS}

1. Na apresentação da obra realizada em conjunto, Wolff, Moore e Marcuse (1970:10) afirmam: "Concluímos todos, ao analisar as teorias e práticas predominantes da tolerância, que elas são, em graus variáveis, máscaras hipócritas a ocultar aterradoras realidades políticas”. Segundo os autores, "o pluralismo é uma teoria de funcionamento das modernas democracias industriais, com especial ênfase nos Estados Unidos. Constitui, outrossim, modelo ideal de como a sociedade devia ser moralmente organizada, seja de fato ou não. Encarada como teoria descritiva, o pluralismo exige comprovação empírica do tipo que legiões de cientistas políticos procuram fornecer em décadas recentes. Vista como teoria normativa, porém, é preciso defendê-la apelando para algum princípio de virtude, ou ideal de boa sociedade. (...) Cada defesa do pluralismo corresponde uma defesa da tolerância" (Wolff et al., 1970:22, 27). Contudo, na sociedade norte-americana, matriz da concepção democrático-pluralista desde a passagem do século XIX para o XX, "encontramos uma mistura da maior tolerância pelo que podería- 
mos denominar grupos tradicionais e uma intolerância igualmente grande pelo dissidente" (Wolff et al., 1970:44). Trata-se de um liberalismo conservador que se funda na tolerância coletiva (redução de conflitos entre grupos antagônicos) e intolerância individual. Enfim, "o pluralismo freia a mudança social" (Wolff et al., 1970:52).

2. É conhecida a meticulosa análise empreendida por Foucault sobre a sociedade disciplinar desde Vigiar e punir. Entretanto, um pequeno artigo anterior ao seu contundente livro, escrito em 1967, orienta algumas reflexões aqui propostas sobre a dessacralização do espaço público, num momento de transferências de comandos da sociedade disciplinar para a sociedade de controle (Foucault, 2001b).

3. Para Hardt e Negri (2000), é preciso inventar uma multidão democrática, reverso da multidão descrita pelos teóricos contratualistas, que não é mais plebe ou povo. É formada não só por cidadãos, mas por trabalhadores intelectuais." Hoje, afirma Negri (2001:31), a "multidão é isso - uma multidão que subtrai ao poder toda transcendência possível e que não pode ser dominada senão de forma parasitária, portanto feroz". Sua compreensão da vida pós-moderna, em que a sociedade se subordina ao capital, caracteriza-se como sendo a fase da biopolítica produtiva. Dizendo atualizar a noção de Foucault, Negri afirma que a biopolítica deixa de ser política descendente do aparelho de Estado (própria da era do Estado-nação). O Estado deixa de ser o sujeito da conexão com a sociedade. Agora, o sujeito que "organiza o conjunto das condições de reprodução da vida da sociedade e não somente da "economia"" (Negri, 2001:35-36) é, ao mesmo tempo, um empreendedor de subjetividade e de igualdade. É o empreendedor biopolítico que vive um máximo de liberdade e de ruptura em relação à disciplina da fábrica. Este é o trabalhador intelectual realizando "um franciscanismo laico e ateu" (Negri, 2001:51), ocupando o tempo de cada um com responsabilidades. O comunismo de Marx é redimensionado como a "multidão que se torna comum" (Negri, 2001:32). Negri circunscreve-se ao campo anexo ao da compaixão cívica, caracterizado por Sennett (1997) como campo das carências, de retomada dos desvios da "compreensão religiosa". Ao imaginar opor resistências reescreve relações de poder na sociedade de controle, que recomenda participação constante e responsável. A outra globalização é a máscara complementar para o uso do mesmo rosto (da mesma maneira que capitalismo e socialismo autoritário se ajustavam à sociedade disciplinar). Negri redimensiona Marx para a fase em que o trabalho intelectual prepondera na globalização capitalista, sem que fosse necessária a passagem para o socialismo. Ressoa em seu projeto uma esperança de retomada dos sovietes pré-revolução de outubro de 1917: a nova mesma multidão com suas diversidades suprimidas a partir da hegemonia bolchevista.

4. Guilherme Castelo Branco informa que escolheu a "expressão assujeitamento ao invés de sujeitamento para seguir à risca a idéia de Foucault: trata-se de um modo de realização do controle da subjetividade pela constituição mesma da individualidade, ou seja, da construção de uma subjetividade dobrada sobre si e cindida dos outros. Dentre as lutas de resistências, as que se prestam ao foco de Foucault são as lutas contra "o assujeitamento, contra as diversas formas de subjetividade e submissão" (Castelo Branco, 2000:326, 315).

5. Sobre a relação interior-exterior, incluindo uma nova atuação das ciências humanas, "trata-se doravante de proteger um cosmos no interior do qual voltamos a nos tornar uma mera parte, mesmo que seja uma parte motriz. Hoje, lutamos entre nós, os homens, pelos belos olhos de uma natureza violada que se tornou miserável e frágil, mas englobante. Todos os combates por uma parte dos meios ambientes são combates contra grupos sociais" (Latour; Schwartz; Charvolin, 1998:96).

6. "Certos silêncios podem implicar hostilidade virulenta; outros, por outro lado, são indicativos de uma amizade profunda, de uma admira- ção emocionada, de um amor. Eu lembro muito bem que quando eu encontrei o cineasta Daniel Schmid, vindo me visitar, não sei mais com que propósito ele e eu descobrimos, ao fim de alguns minutos, que nós não tínhamos verdadeiramente nada a nos dizer. Desta forma, ficamos juntos desde as três horas da tarde até meia-noite. Bebemos, fumamos haxixe, jantamos. Eu não creio que tenhamos falado mais do que vinte minutos durante essas dez horas. Este foi o ponto de partida de uma amizade bastante longa. Era, para mim, a primeira vez que uma amizade nascia de uma relação estritamente silenciosa" (Foucault, 1994:525).

\section{REFERÊNCIAS BIBLIOGRÁFICAS}

BOURDIEU, P. De l'État social a l'État penal, Actes de la Recherche em Sciences Sociales, Paris, Seuil, n.124, 1998.

CASTELO BRANCO, G. Considerações sobre a ética e a política, In: PORTOCARRERO, V.; CASTELO BRANCO, G. (Orgs.). Retratos de Foucault. Rio de Janeiro: Nau, 2000. p. 310-327.

DELEUZE, G. Conversações. Rio de Janeiro: 34 Letras, 1992.

$$
\text { . Foucault. São Paulo: Brasiliense, } 1988 .
$$

FERRUA, P.J.C., anarquista fichado no Brasil. Verve, São Paulo, Núcleo de Sociabilidade Libertária do Programa de Estudos PósGraduados em Ciências Sociais da PUC-SP, n.4, p.20-31, 2003.

FOUCAULT, M. Os anormais. São Paulo: Martins Fontes, 2001a.

. Outros espaços (1967). In: MOTTA, M.B. (Org.). Ditos e escritos. Estética: literatura e pintura, música e cinema. Rio de Janeiro: Forense Universitária, 2001b. v.III, p.411422 .

An Interview with Stephen Riggins (1982). In:

DEFERT, D.; EWALD, F. (Orgs.). Michel Foucault, dits et écrits. Paris: Gallimard, 1994. v.IV, p.525-538.

GIDDENS, A. Para além da esquerda e da direita. São Paulo: Unesp, 1995.

HARDT, M.; NEGRI, A. Império. São Paulo: Record, 2000.

LATOUR, B.; SCHWARTZ, C.; CHARVOLIN, F. Crise dos meios ambientes: desafios às ciências humanas. In: ARAUJO, H.R. (Org.). Tecnologia e cultura, ensaios sobre o tempo presente. São Paulo: Estação Liberdade, 1998. p.91-125.

PASSETTI, E. Anarquismos e sociedade de controle. São Paulo: Cortez, 2003.

NEGRI, T. Exílio. São Paulo: Iluminuras, 2001.

SENNETT, R. Corpo e pedra. Rio de Janeiro: Record, 1997.

TRAGTENBERG, M. Burocracia e ideologia. São Paulo: Ática, 1974.

WACQUANT, L. As prisões da miséria. Rio de Janeiro: Jorge Zahar, 2002.

WOLFF, P.R.; MOORE, B.; MARCUSE, H. Crítica da tolerância pura. Rio de Janeiro: Zahar, 1970.

Edson Passetti: Professor do Departamento de Politica do Programa de Estudos Pós-Graduados em Ciências Sociais e Coordenador do Núcleo de Sociabilidade Libertária da PUC-SP. 